\title{
OPEN Inactivation efficacy of atmospheric air plasma and airborne acoustic ultrasound against bacterial biofilms
}

\begin{abstract}
Apurva D. Patange ${ }^{1 凶}$, Jeremy C. Simpson ${ }^{2}$, James F. Curtin ${ }^{3}$, Catherine M. Burgess ${ }^{4}$, P. J. Cullen ${ }^{3,5}$ \& Brijesh K. Tiwari ${ }^{1}$

Biofilms are complex microbial communities that present serious contamination risks to our environment and health. In this study, atmospheric air plasma and airborne acoustic ultrasound technology were applied to inactivate Escherichia coli and Listeria innocua biofilms. Both technologies were efficient in controlling, or completely inactivating, the target bacterial biofilms. Viability and metabolic assays, along with microscopy analysis, revealed that atmospheric air plasma and airborne acoustic ultrasound damaged both the bacterial biofilm cells and its structural integrity. Scanning electron microscopy images highlighted the disruption of the biofilms and pore formation in bacterial cells exposed to both the plasma and acoustic treatments. Elevated reactive oxygen and nitrogen species in bacterial cells treated with atmospheric air plasma, demonstrated their primary role in the observed bacterial inactivation process. Our findings provide potential antimicrobial strategies to combat bacterial biofilms in the food and healthcare sectors.
\end{abstract}

Biofilms consist of a diverse variety of bacteria embedded together in a gel-like matrix of extracellular polymeric substances (EPS) and nucleic acids. They aggregate and grow in micro-colonies by attaching to abiotic or biotic surfaces or interfaces, causing a wide variety of difficulties for industrial and clinical settings. Active dispersal mechanisms of biofilms result in the colonisation of new areas, as well as acting as an important source of crosscontamination. Biofilms are responsible for several chronic infections, food spoilage, and equipment damage, resulting in considerable economic and public health problems ${ }^{1-3}$. Biofilms are highly organised structures; their self-produced EPS serves as a multi-layer physical barrier for the embedded bacteria against environmental and antimicrobial stresses ${ }^{4}$. Conventional methods of decontamination are often ineffective or inadequate for biofilms due to their complex composition and structure ${ }^{5,6}$. The persistence of infections and resistance to conventional treatments enabled by biofilm formation are major causes of treatment failure. Protected cells serve as a reservoir for continuous contamination and provide an environment where antimicrobial-injured cells can repair cellular damage and re-grow. In an effort to find an efficient method to control biofilm, several technology-based methods have emerged as potential alternatives to traditional treatment methods.

The antimicrobial nature of cold plasma technology has been well demonstrated in several recent studies ${ }^{7-9}$. Different types of plasma reactors have been used for disinfection and decontamination of microorganisms depending, on the substrate treated and their applications in the areas of biological decontamination. Plasma effects on bacterial cells are mediated by biological activators such as charged particles, electrons and ions, electric field, UV radiation and reactive oxygen and nitrogen species (RONS) such as hydrogen peroxide, singlet oxygen molecules, nitrate and nitrite ${ }^{10}$. Adverse influences of atmospheric air plasma (AAP) on bacteria include cellular membrane damage, alteration in structure, biological and genetic responses. Due to the numerous inactivation mechanisms, AAP has proved to be a promising treatment technology against most spoilage and pathogenic bacteria.

Ultrasound has demonstrated successful application in the food industry for drying, extraction defoaming and decontamination ${ }^{11,12}$ as well as in clinical settings for chronic wound care and healing ${ }^{13,14}$. The ultrasound

\footnotetext{
${ }^{1}$ Food Chemistry and Technology Department, Teagasc Food Research Centre, Ashtown, Dublin, Ireland. ${ }^{2}$ School of Biology and Environmental Science, University College Dublin, Dublin, Ireland. ${ }^{3}$ School of Food Science and Environmental Health, Technological University Dublin, Dublin, Ireland. ${ }^{4}$ Food Safety Department, Teagasc Food Research Centre, Ashtown, Dublin, Ireland. ${ }^{5}$ School of Chemical and Biomolecular Engineering, The University of Sydney, Sydney, Australia. ${ }^{\square}$ email: apurvapatange@gmail.com
} 
produces pressure sound waves with frequencies of $20 \mathrm{kHz}$ or more; with a threshold limit beyond human hearing. The bactericidal effect of ultrasound is mainly due to mechanical and chemical energy including shock waves, shear stress, pressure, agitation, vibration and cavitation ${ }^{15}$. Stable cavitation and pressure create multidirectional acoustic micro-jets that puncture the proximal bacterial cell membrane and damage microorganisms ${ }^{16}$. Several studies have examined various contact-type ultrasound systems. However, recent technology advances have shown the benefits of using non-contact airborne acoustic ultrasound for various food and non-food applications ${ }^{11}$. Acoustic airborne ultrasound employs non-contact transducers transmitting ultrasonic waves to treat products, using air as the coupling medium. Moreover, the use of airborne acoustics ultrasound does not restrict treatment to liquids or solid immersed in liquids but can be applied to products where there are no liquids by using tuned transducers. Despite the growing literature, information on the efficacy of non-contact acoustic airborne ultrasound against microbes, and specifically against bacterial biofilms, is limited. This study presents a comprehensive investigation of two air-based non-thermal technologies namely atmospheric air plasma (AAP) and airborne acoustic ultrasound (AAU) against early and mature bacterial biofilms grown on inanimate surfaces.

\section{Results and discussion}

Effect of plasma frequency variation on physiochemical properties. The $\mathrm{pH}$ values for distilled water decreased from 6.5 to 3.0 or 2.74 or 2.70 , depending on the system frequency. There was no significant difference observed between the $\mathrm{pH}$ measured at different plasma treatment frequencies. The low $\mathrm{pH}$ values suggest increased RONS concentrations in the liquid after plasma treatment. The acidic conditions in the water caused by plasma using air as the working gas is likely to be due to nitric acid production, where nitrogen and oxygen react with water to form the following acids:

$$
\begin{gathered}
\mathrm{NO}_{2}{ }^{-}+\mathrm{H}^{+} \rightarrow \mathrm{HNO}_{2} \\
\mathrm{NO}_{2}+\mathrm{OH} \rightarrow \mathrm{HNO}_{3} \\
\mathrm{NO}_{2}{ }^{-}+\mathrm{H}_{2} \mathrm{O}_{2}+\mathrm{H}^{+} \rightarrow \mathrm{NO}_{3}^{-}+\mathrm{H}_{2} \mathrm{O}+\mathrm{H}^{+}
\end{gathered}
$$

As shown in Fig. 1, high concentrations of nitrate were detected after 5 min of plasma treatment; moreover, the concentrations were further increased at the higher frequency of $2500 \mathrm{~Hz}$. Additionally, small concentrations of hydrogen peroxide and nitrite were also detected. Owing to the longer treatment and acidic conditions, nitrite can degrade and transform into nitrates ${ }^{17}$. Moreover, hydrogen peroxide reacts with nitrites to form nitrates or peroxynitrites ${ }^{17}$. No significant difference was observed in hydrogen peroxide and nitrites detected at different plasma treatment frequencies, except in the case of nitrates.

Depending on the plasma characteristics, higher frequency can significantly increase discharge current, power, gas conductivity which in turn could increase reactive species in a sample ${ }^{18,19}$. In this study, higher frequency resulted in a higher concentration of nitrates. Plasma generated reactive species are important factors in cold plasma treatment; they act synergistically with acidic $\mathrm{pH}$, create favourable conditions for the penetration of RONS into the cell membrane ${ }^{20}$. It would therefore be expected that increasing the frequency (in this case) would influence bacterial inactivation efficacy, yielding improved plasma-mediated biofilm eradication. Therefore, a constant operating frequency of $2500 \mathrm{~Hz}$ was chosen for all further experiments.

Analysis of intracellular reactive species generated by atmospheric air plasma treatment. Biofilm has complex defence systems that help protect embedded cells in the EPS to maintain homeostasis and help protect cells located deeper within the matrix from disinfectants by permitting only limited diffusion of chemicals. Therefore, this study also investigated reactive oxygen and nitrogen species (RONS) within biofilm cells post AAP treatment. Data shown in Fig. 2 represents the intracellular RONS concentrations generated after AAP treatment expressed as mean fluorescence intensity (\%). The results show that AAP-exposed cells had significantly augmented DCFH-DA and DAF-FM DA intensity, indicating significant increases in intracellular RONS levels. In particular, after 5 min of plasma exposure, ROS levels and RNS levels were more than twice that of the untreated controls. The gradual rise in the DCF and DAF intensity suggests the accumulation of intracellular ROS and RNS in biofilm cells with increasing AAP treatment. Previous studies have also found significant $(\mathrm{P}<0.05)$ increases in intracellular ROS in Listeria monocytogenes (EGD-e) cells after dielectric barrier discharge cold plasma treatments ${ }^{21}$. Long plasma treatment produced higher reactive species which caused oxidative stress in L. monocytogenes cells, which was indicated by higher intracellular ROS levels. The study also demonstrated significant up-regulated oxidative stress response genes with increasing plasma treatments. The combined interaction of plasma constituents, electric fields, ions and electrons, along with biological cellular components could invoke oxidative responses in bacteria, inducing many detrimental effects on biofilms.

Effect of atmospheric air plasma treatment and airborne acoustic ultrasound treatment on cultivability and metabolic activity of bacterial biofilms. To evaluate the abilities of atmospheric air plasma and airborne acoustic ultrasound technology to inactivate bacterial biofilms, E. coli and L. innocua biofilms were exposed to AAP or AAU for different treatment times. The plate count assay indicated the bactericidal effect of both AAP and AAU treatments (Fig. 3). Both treatments significantly reduced E. coli and L. innocua biofilm populations. An AAP treatment of $5 \mathrm{~min}$ was able to inactivate $48 \mathrm{~h}$ biofilm cells below the detection limit (l $\log \mathrm{CFUcm}^{2}$ ), while airborne acoustic treatment of $30 \mathrm{~min}$ reduced the E. coli and L. innocua counts by 3.42 and $4.05 \log _{10}$ CFU/coupon, respectively. The maturity of the biofilm significantly influenced the antimicrobial efficacy of the atmospheric air plasma and airborne acoustic ultrasound process. For $96 \mathrm{~h}$ biofilms, it was observed 


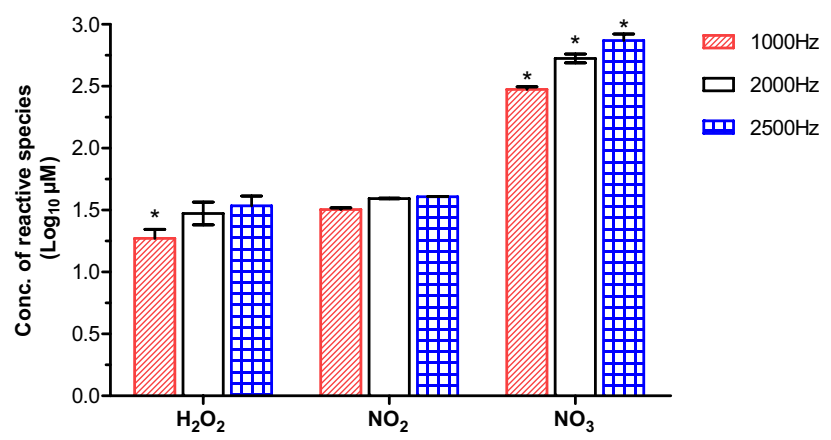

(a)

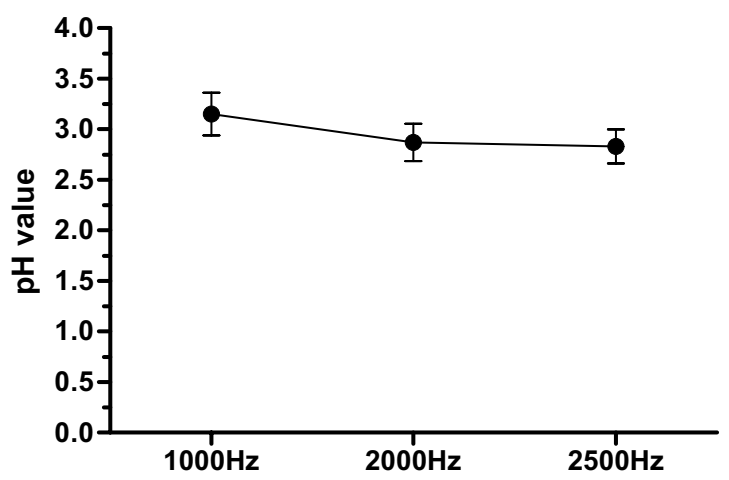

(b)

Figure 1. (a) Concentration of reactive oxygen/nitrogen species (RONS) and (b) pH values measured in water treated with a plasma pin-reactor at different system frequencies for a treatment time of 5 min. Error bars indicate standard deviation. Data were collected from two independent experiments, each one performed in duplicate $(n=4)$. Asterisk $\left(^{*}\right)$ represents significant difference $(\mathrm{p} \leq 0.05)$ between different plasma system frequencies for each reactive species $\left(\mathrm{H}_{2} \mathrm{O}_{2}\right.$ or $\mathrm{NO}_{2}$ or $\left.\mathrm{NO}_{3}\right)$. Graphs were generated using GraphPad Prism version 5.0 (GraphPad Software, San Diego, California USA, http://www.graphpad.com).

that both the non-thermal treatments were less effective than for the $48 \mathrm{~h}$ biofilms. This could be explained by the fact that mature biofilms are denser in biofilm mass than younger ones, limiting diffusion of antimicrobial agents into the biofilm matrix ${ }^{22}$. Longer AAP treatment periods were required for the $96 \mathrm{~h}$ biofilm cells to reduce the bacterial population to undetectable levels. As observed with intracellular RONS results, increasing plasma treatment time, there were more reactive species produced inside the cell. The longer treatment time allowed more reactive plasma species to penetrate the biofilm matrix, interact with the cells and oxidize them, resulting in a stronger inactivation effect, even with increased biofilm age. Similarly, Soler-Arango et al. ${ }^{23}$ found a strong bactericidal effect of gas discharge plasma treatment that reduced the concentration of the Pseudomonas aeruginosa biofilms by $3.4 \mathrm{log} \mathrm{CFU} / \mathrm{mL}$ after $3 \mathrm{~min}$ of plasma exposure and complete deactivation ( $99.999 \%$ killing efficacy) after 15-min plasma treatment.

In the case of ultrasound treatment, no significant changes were evident between 15- and 30-min treatments. Previous research by Bi et al. ${ }^{24}$ found that inactivation of Salmonella typhimurium cells was relatively rapid for an initial treatment period of $20 \mathrm{~min}$ with a contact-type ultrasound treatment, but was followed by a tailing effect for longer treatments. The resistance of E. coli and L. innocua biofilms towards AAU treatment could be due to the protective nature of the biofilm's structure. Overall, the bactericidal effects of atmospheric air plasma on E. coli and L. innосиa were greater than that of airborne acoustic ultrasound in both early and mature biofilm cultures.

As air plasma and airborne acoustic ultrasound treatment affect biofilm, they may impact enzymatic activity associated with the metabolic activity of the cell. The effects of both AAP and AAU treatments on the metabolic activity of $96 \mathrm{~h} \mathrm{E}$. coli and L. innocua biofilm cells were evaluated by a calorimetric method using the XTT assay. As shown in Fig. 4, 3 min AAP exposure resulted in a 45\% reduction in metabolic activities of both E. coli and $L$. innocua cells. In the case of bacterial cells exposed to 15 min AAU, the metabolic activity of E. coli and $L$. innocua cells were reduced by $55 \%$ and $63 \%$, respectively. The metabolic activity of E. coli and L. innocua cells demonstrated a gradual reduction with increasing AAP treatment, while there was no significant difference observed between 15 and $30 \mathrm{~min}$ for AAU treated cells. This is in agreement with the culturable plate count data. Biofilm cells treated with 10 min AAP, which were below the detection limit as measured by the plate count method, indicated metabolic activity. These results suggest the presence of viable-but-non-culturable (VBNC) or persister cells; where cells are dormant, slow-growing (that were below detection limit by plate count assay), 


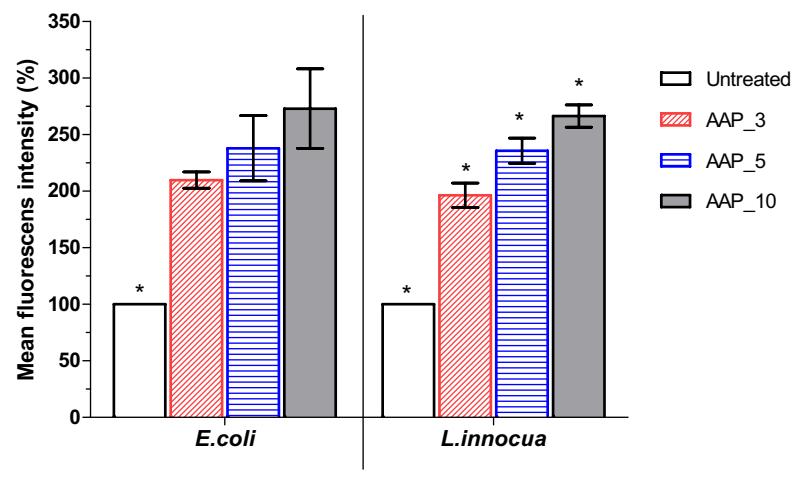

(a)

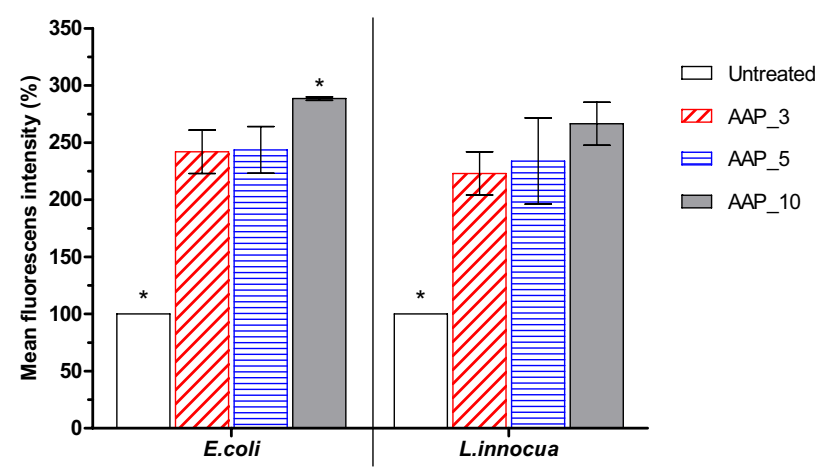

(b)

Figure 2. Intracellular levels of RONS in E. coli and L. innocua $96 \mathrm{~h}$ biofilm cells after atmospheric air plasma treatment (a) ROS (b) RNS levels. Data are the mean percentage values of fluorescence intensity. Results represent the average of two independent experiments, each one performed in triplicate $(n=6)$. Statistical analysis and graphs were generated using GraphPad Prism version 5.0 (GraphPad Software, San Diego, California USA, http://www.graphpad.com). Separate one-way ANOVA tests were performed for each biofilm forming species to make a comparison between the untreated control and the different atmospheric air plasma treatments. Asterisk indicates significance difference $(\mathrm{p} \leq 0.05)$. AAU_15: airborne acoustic ultrasound treatment for $15 \mathrm{~min}$; AAU_30: airborne acoustic ultrasound treatment for $30 \mathrm{~min}$; AAP_3: atmospheric air plasma treatment for 3 min; AAP_5: atmospheric air plasma treatment for $5 \mathrm{~min}$; AAP_10: atmospheric air plasma treatment for $10 \mathrm{~min}$.

or in a non-growing state, which was also referred to by Gilmore et al. ${ }^{25}$ and Ziuzina et al. ${ }^{26}$. The VBNC state generally occurs when bacteria are under stress conditions such as oxidative stress, starvation, acidic, osmotic and other adverse conditions.

Effect of atmospheric air plasma and airborne acoustic ultrasound on viability, membrane integrity and bacterial morphology of biofilm cells.. To evaluate the effect of AAP and AAU on the viability of cells embedded in the biofilm, E. coli biofilm cells were stained with SYTO 9 and propidium iodide (PI) for examination by fluorescence Live/Dead assay and confocal laser scanning microscopy (CLSM). The confocal images acquired from SYTO/PI stained E. coli biofilms before and after treatment are displayed in Fig. 5a-e. The untreated biofilm cells were predominantly green, indicating that a large number of cells present were live cells. With AAU and AAP treatment, green live cells diminished gradually, and the fraction of red dead cells increased, indicating that the vast proportion of the biofilm cells were dead which further corroborated the findings obtained from the plate count experiments. The fluorescence Live/Dead assay, which was used to quantify the viability of the cells after AAP and AAU treatment, also showed a decline in live cells (Fig. 5f). After AAU treatment (15- and 30- min), a large number of cells were dead; the percentage of live cells were reduced to 31 and $33 \%$. As the plasma processing time increased, the percentage of live cells with intact membranes decreased in a plasma dose-dependent manner.

In order to gain a deeper understanding of the plasma/ultrasound-induced changes in bacterial morphology and cell injury, SEM analysis was performed on E. coli biofilms (Fig. 6). The untreated samples revealed a large amount of rod-shaped $E$. coli cells with interspersed extracellular polymeric substance (EPS) observed on cells and between cells and the coupon surfaces. Compared to the untreated controls, there were considerable morphological alterations and structural damages observed post-treatment. After AAU and AAP treatment a large 


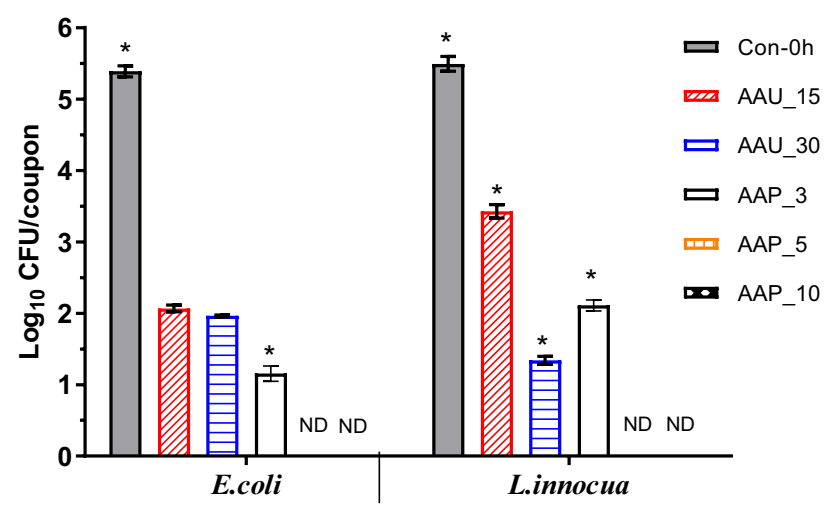

(a)

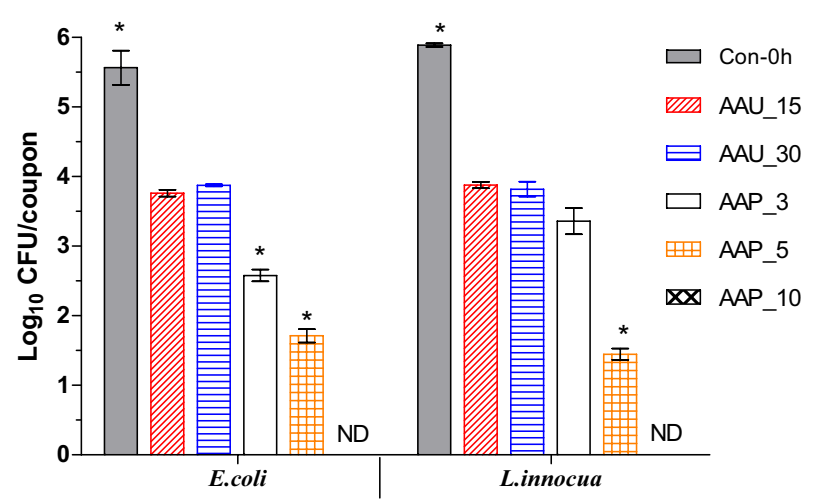

(b)

Figure 3. Inactivation efficacy of airborne acoustic ultrasound and atmospheric air plasma technology against (a) $48 \mathrm{~h}$ and (b) $96 \mathrm{~h} \mathrm{E}$. coli and L. innocua biofilms. ND: not detected, below detection limit. Vertical error bars indicate standard deviation $(n=4)$. Asterisk indicates significant differences $(p \leq 0.05)$ between different treatments for each bacterial strain, analysed by one-way ANOVA and Tukey multiple comparison post hoc test. Graphs were generated using GraphPad Prism version 5.0 (GraphPad Software, San Diego, California USA, http://www.graphpad.com). AAU_15: airborne acoustic ultrasound treatment for 15 min; AAU_30: airborne acoustic ultrasound treatment for $30 \mathrm{~min}$; AAP_3: atmospheric air plasma treatment for $3 \mathrm{~min}$; AAP_5: atmospheric air plasma treatment for $5 \mathrm{~min}$; AAP_10: atmospheric air plasma treatment for $10 \mathrm{~min}$.

proportion of E. coli cells were disintegrated, and cell debris was found on the surface. Furthermore, some E. coli cells showed pore formation and localised ruptures after treatment. This indicates both treatments physically affected the biofilm and cell structure of the bacteria. From the morphology study, the maximum physical effects were observed after 30 min of AAU and 5-10 min of AAP treatment. In the SEM images (Fig. 6e), the majority of the EPS layer was removed after 5 min of plasma treatment. Notably, in some areas, the bacterial cells appeared rough but still intact. It should be noted that an undamaged cell morphology after treatment does not signify a viable cell. In addition to morphological damage, cold plasma or ultrasound treatment also affect intracellular components, including DNA, protein, as well as enzymes.

The physical effects of AAP have been well recognised as one of the major modes of bacterial inactivation ${ }^{20,27}$. Although cold plasma treatment can kill bacteria, damage biofilm matrix and affect EPS, the mechanisms underlying its effects are unclear. The ROS/RNS can penetrate cells and are known to cause oxidative and nitrosative damage to lipids and protein in bacteria. This damage induces lipid peroxidation, inhibition of enzyme functions and alteration of DNA, which ultimately accounts for bacterial cell death ${ }^{27}$. The chemical reaction between reactive species and acidification of the milieu, combined are responsible for the lethality to the microorganism ${ }^{20}$. Previous studies by Los et al. ${ }^{28}$ and Patange et al. ${ }^{9}$ evaluated the disinfection potential of acidified (by HCl) solutions compared to plasma treatment on bacterial biofilm and spores. The study reported a minimum or reduced antimicrobial effect of acidified water compared to plasma treatment. Kondeti et al. ${ }^{29}$ reported acidified hydrogen peroxide solution at the same $\mathrm{pH}$ as cold plasma solution had no inactivation effect on Pseudomonas aeruginosa and Staphylococcus aureus. Similarly, Schnabel et al. ${ }^{30}$ compared inactivation efficacy between plasma treatment and a nitric acid solution; the results demonstrated comparable inactivation rates only with a very strongly acidified $\mathrm{HNO}_{3}$ solution. While $\mathrm{pH}$ supports inactivation, the combined interaction of plasma constituents and 


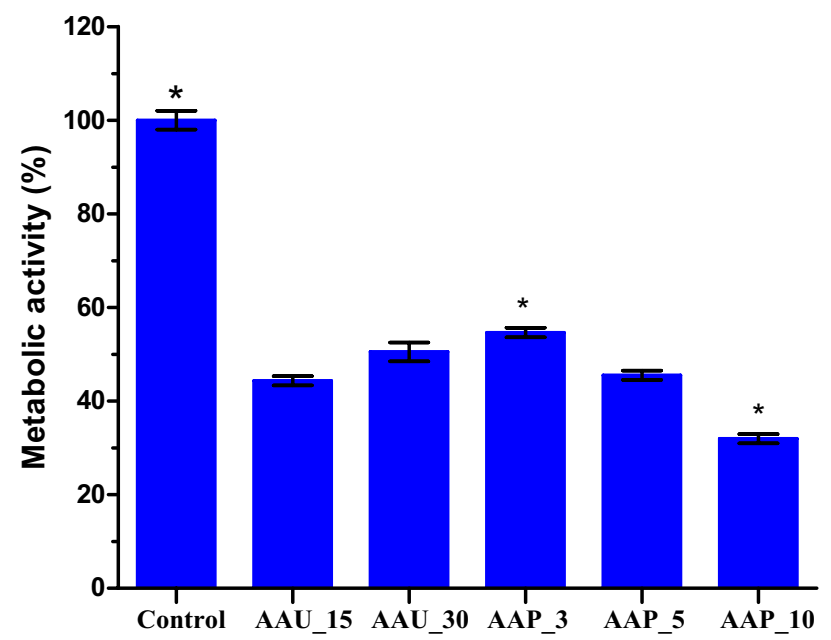

(a)

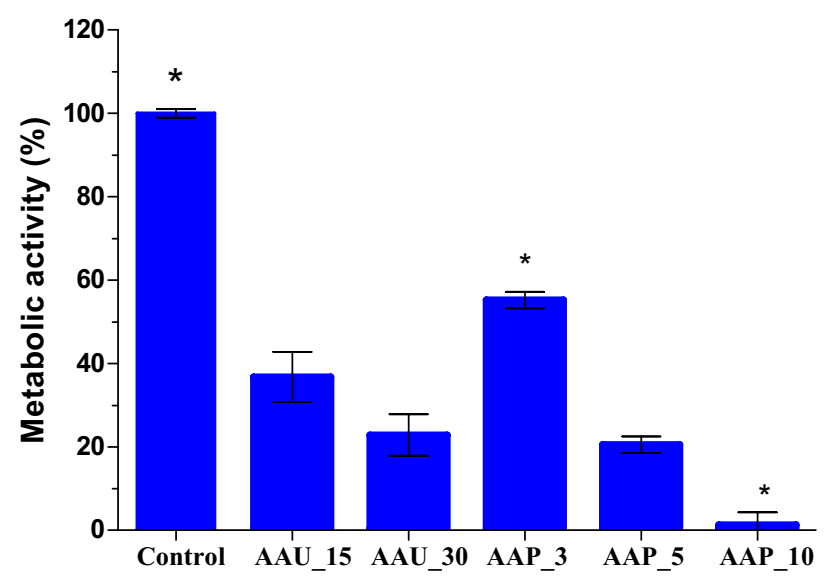

(b)

Figure 4. Effect of airborne acoustic ultrasound and atmospheric air plasma treatment on metabolic activity of $96 \mathrm{~h}$ (a) E. coli and (b) L. innocua biofilms. Error bars indicate standard deviation $(\mathrm{n}=4)$. Significant differences between different treatments are marked by asterisks $(\mathrm{P}<0.05$; One-way ANOVA test and Tukey multiple comparison post hoc test). Graphs were generated using GraphPad Prism version 5.0 (GraphPad Software, San Diego, California USA, http://www.graphpad.com). AAU_15: airborne acoustic ultrasound treatment for 15 min; AAU_30: airborne acoustic ultrasound treatment for 30 min; AAP_3: atmospheric air plasma treatment for $3 \mathrm{~min}$; AAP_5: atmospheric air plasma treatment for $5 \mathrm{~min}$; AAP_10: atmospheric air plasma treatment for $10 \mathrm{~min}$.

acidification causes oxidative stress in bacteria and its intracellular components, ultimately inducing adverse effects on biofilms.

In the case of AAU, the rapid series of contraction and expansion of acoustic pressure are speculated to deliver the observed mechanical effects on bacteria ${ }^{11}$. Absorption of acoustic energy by the bacteria, may alter the cell morphology and disrupt cell membrane integrity. The high acoustic pressure could also enhance ultrasonic wave stress-causing pores in cell membranes, eventually causing cell death. There have been numerous studies examining the antimicrobial efficacy of ultrasound in food ${ }^{12}$; however, most of these studies employed contact-based ultrasound treatment. The acoustic intensity used in this study was significantly low. The exact mechanism of microbial biofilm inactivation by non-contact type ultrasound is not yet fully understood and needs to be further explored.

Comparison of the inactivation efficacy of sodium hypochlorite, atmospheric air plasma and airborne acoustic ultrasound system against $E$. coli biofilm. An additional experiment was performed to compare the antimicrobial effect of atmospheric air plasma, airborne acoustic ultrasound treatment with a commonly used disinfectant such as sodium hypochlorite. Chlorine and chlorine-based products are 


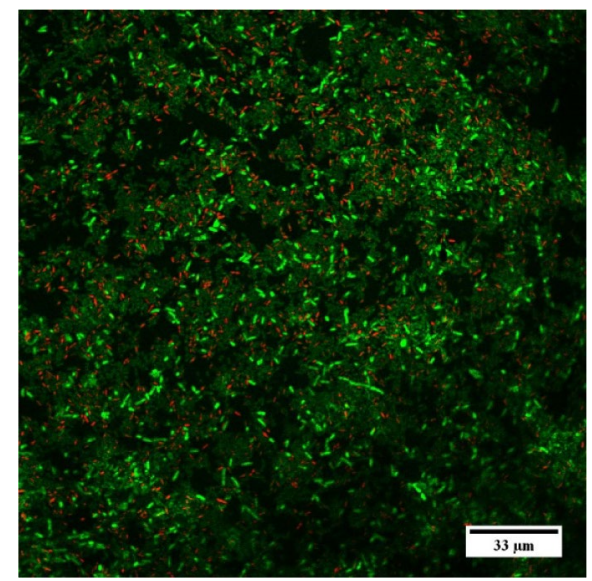

(a)

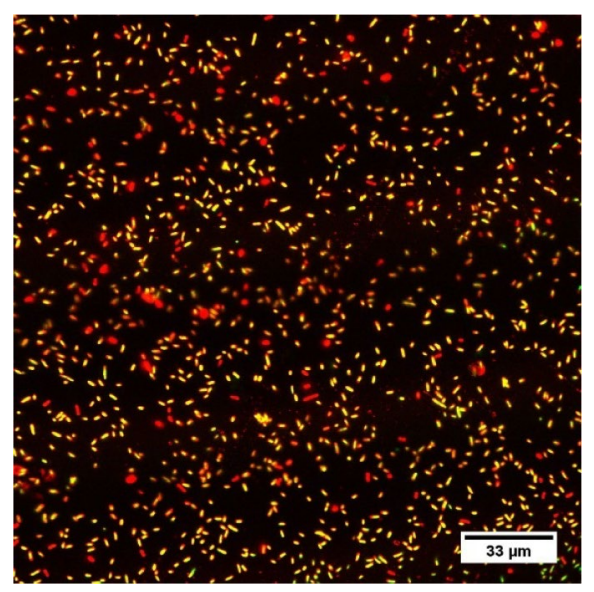

(c)

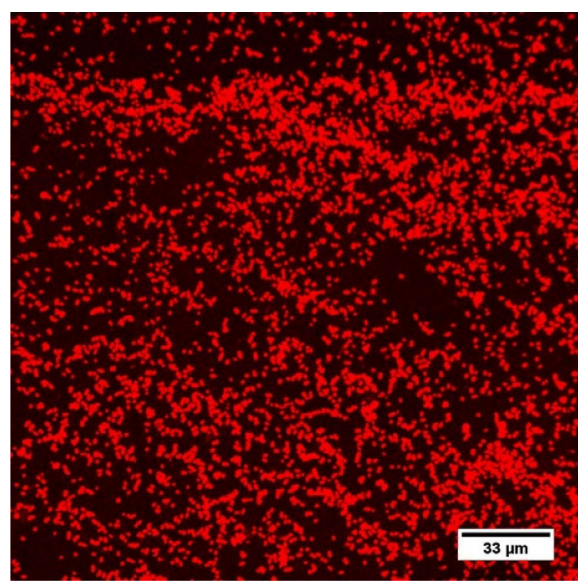

(e)

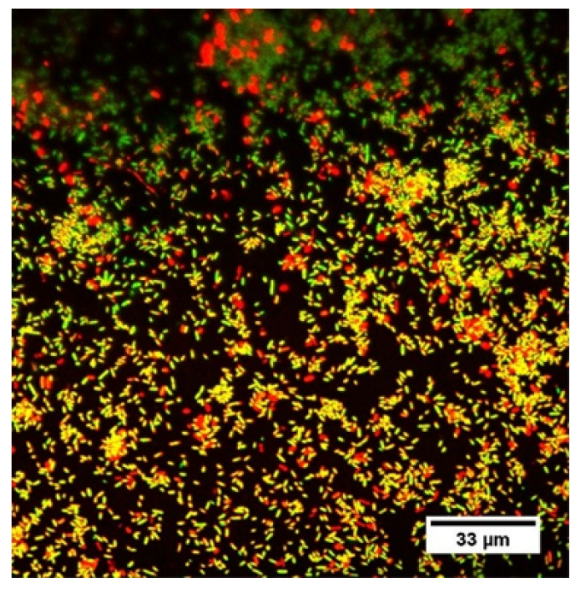

(b)

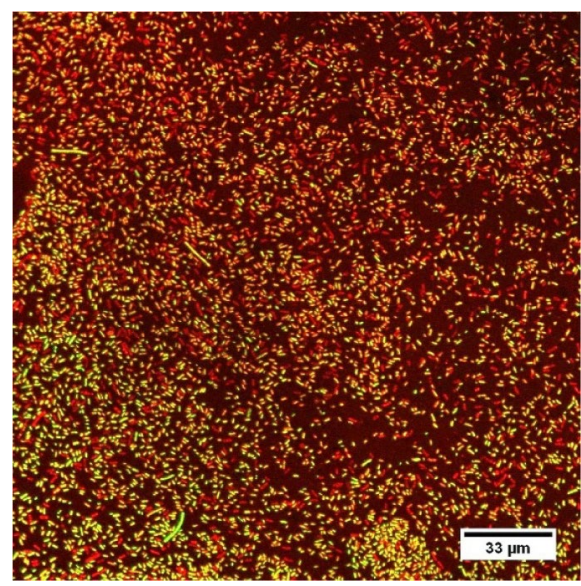

(d)

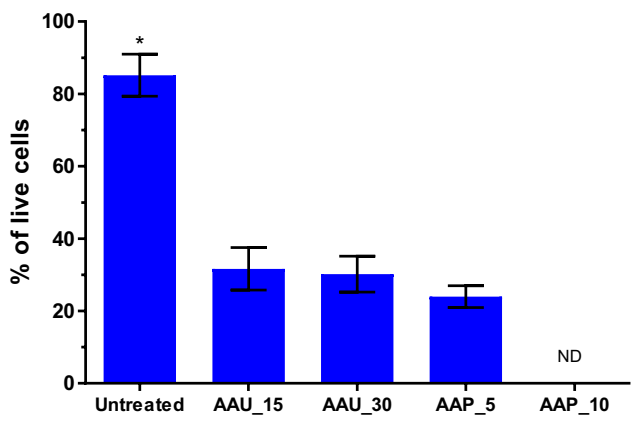

(f)

Figure 5. (a-e) Confocal laser scanning microscopy images of E. coli $96 \mathrm{~h}$ biofilm stained with Live/Dead stain (a) untreated control; (b) 15 min AAU treatment; (c) 30 min AAU treatment; (d) 5 min AAP treatment; (e) $10 \mathrm{~min}$ AAP treatment. Scale bars $=33 \mu \mathrm{m}$. SYTO 9 (green cells) denotes live viable cells, whereas the propidium iodide (red/yellow cells) indicates dead cells that have been deactivated because of ruptured or damaged membranes; (f) percentage of live viable cells after AAU and AAP treatments $(n=6)$. The asterisk indicates significance difference between different treatments $(\mathrm{p} \leq 0.05)$ analysed by one-way ANOVA and Tukey multiple comparison post hoc test. Graph was generated using GraphPad Prism version 5.0 (GraphPad Software, San Diego, California USA, http://www.graphpad.com). 


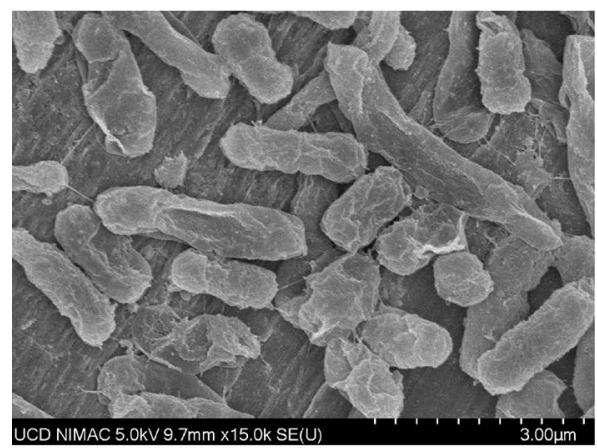

(a)

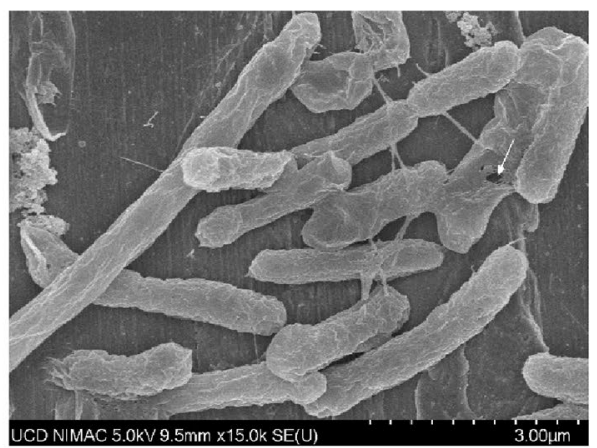

(c)

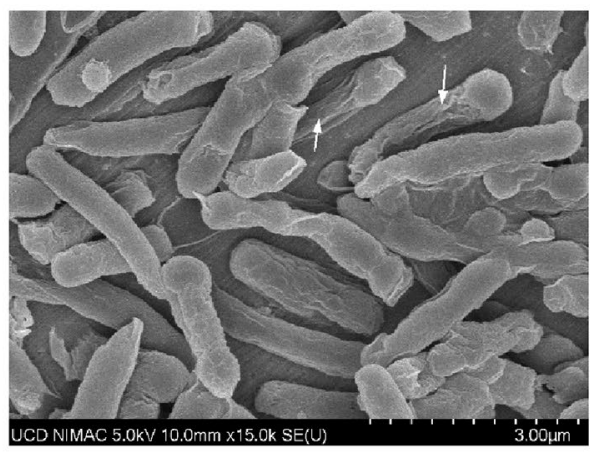

(e)

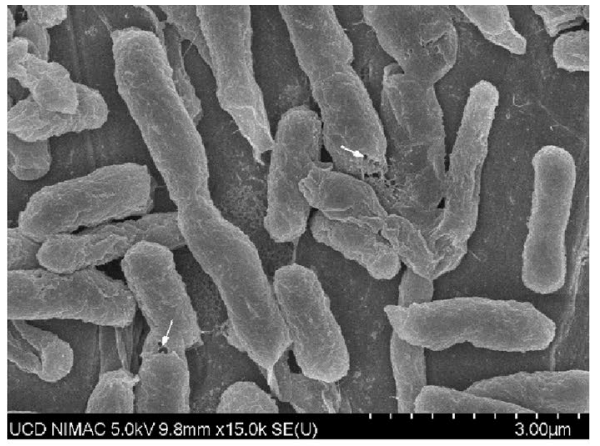

(b)

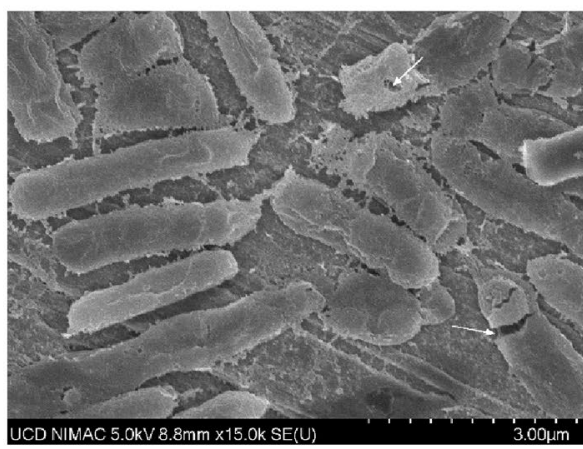

(d)

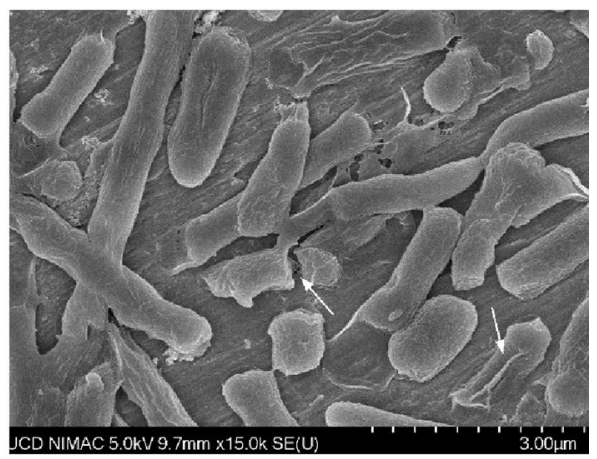

(f)

Figure 6. Scanning electron micrographs of $96 \mathrm{~h}$ E. coli biofilm-(a) Untreated control; (b) 15 min AU treatment; (c) 30 min AAU treatment; (d) 3 min AAP treatment; (e) 5 min AAP treatment; (f) 10 min AAP treatment. White arrows indicate visibly deformed structures and pores.

routinely used as disinfection agents in the food industry and health care sectors for cleaning surfaces, equipment, fresh produce and food contact surfaces ${ }^{31-33}$. The effects of the chlorine solutions on $96 \mathrm{~h} \mathrm{E}$. coli biofilms from SS coupons are shown in Fig. 7. The biofilm population showed a significant reduction of 1.5 Log CFU/ coupon and a $33 \%$ reduction in metabolic activity with an initial $3 \mathrm{~min} \mathrm{NaOCl}$ treatment (200 ppm), compared to untreated controls. However, no further significant inhibition was observed in biofilm cells exposed to longer $\mathrm{NaOCl}$ treatments (5-30 min); the bacterial population remained between 3.6 and 3.2 Log CFU/coupon, suggesting no further killing of cells. A similar phenomenon was observed with the metabolic activity of the biofilm cells exposed to $\mathrm{NaOCl}$ for a longer treatment time. With the technology-based treatments, a greater bactericidal effect was observed with AAP when compared to $\mathrm{NaOCl}$, whereas AAU showed similar effects to $\mathrm{NaOCl}$.

In order to maintain chlorine disinfection efficiency, the food industry has to constantly maintain the active chlorine concentration. The continuous addition of chlorine and its reaction with organic components found in the food industry can produce chlorine by-products, which have potential carcinogenic and mutagenic compounds ${ }^{34,35}$. Furthermore, studies have reported the capability of microorganisms to develop resistance to chlorine-based treatment, where microbes can survive and grow despite biocidal treatments ${ }^{36,37}$. These findings demonstrate the great potential of AAP and AAU for the elimination of bacterial biofilms and their suitability for substituting for the more traditional chlorine-based treatments used in the food industry and healthcare sectors. 


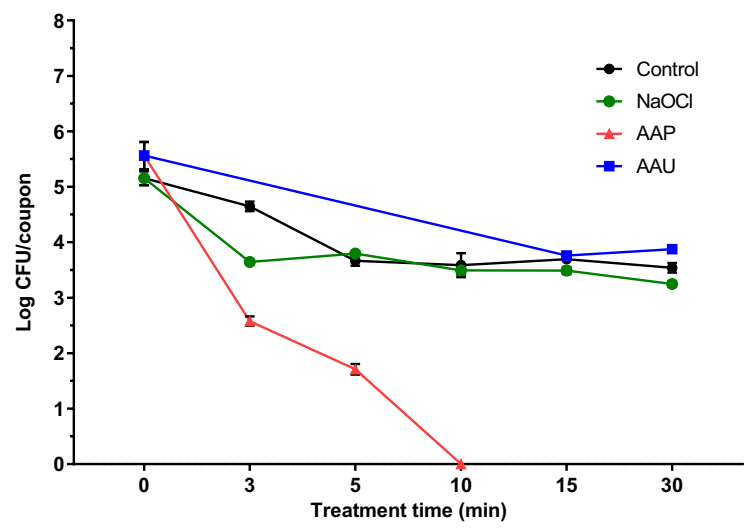

(a)

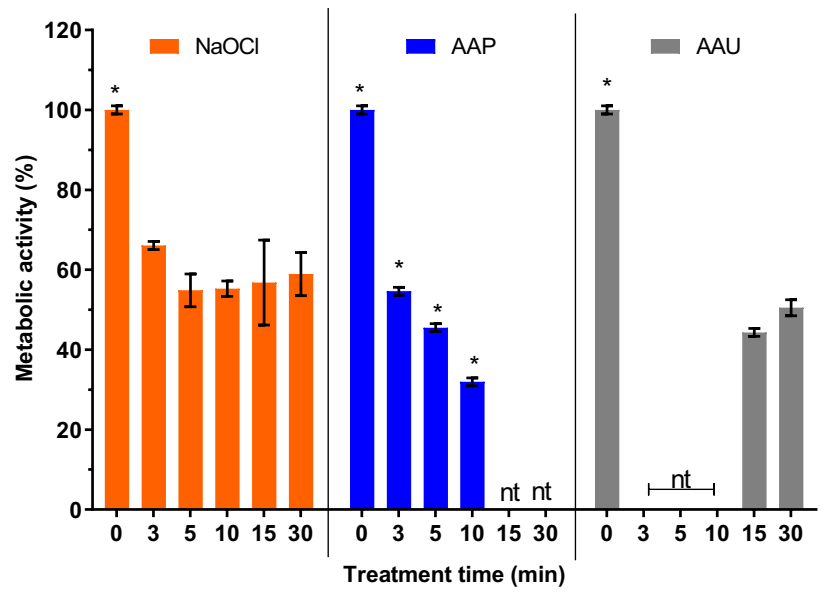

(b)

Figure 7. Effects of sodium hypochlorite ( $\mathrm{NaOCl} ; 200 \mathrm{ppm}$ ), atmospheric air plasma and airborne acoustic ultrasound treatments on $96 \mathrm{~h}$ E. coli biofilms-effect on (a) culturability (Log CFU/coupon) and (b) metabolic activity (\%). Error bars show the standard deviation $(n=4) . n t=$ not treated. The asterisk mark indicates significance difference between different treatments $(\mathrm{p} \leq 0.05)$ analysed by one-way ANOVA and Tukey multiple comparison post hoc test. Graph was generated using GraphPad Prism version 5.0 (GraphPad Software, San Diego, California USA, http://www.graphpad.com).

\section{Conclusion}

Based on findings from this study, it can be concluded that both atmospheric air technologies assessed demonstrated biofilm cell inactivation effects for E. coli and L. innocua biofilms. Atmospheric air plasma treatment was more effective for both early and mature stage biofilms than the airborne acoustic ultrasound treatment. Treatment for 5 min by AAP significantly reduced E. coli and L. innocua biofilm cell counts by 3.5 to 4.5 Log $\mathrm{CFU} /$ coupon, as well as reducing the metabolic activity by $54 \%$. This could be mainly attributed to increased intracellular RONS observed in the treated cells, causing oxidative stress within the cells and consequently accelerating death of the bacterial cells. The results obtained from SEM and CLSM indicated that both AAU and AAP affected the biofilm cell morphology and cell viability. The degree of damage and inactivation obtained with this study suggest the potential to improve or optimise disinfection strategies using a combination of airborne acoustic ultrasound and atmospheric air plasma treatments against complex bacterial biofilms. However, more investigation is necessary to have a better understanding of the reactive species' distribution, penetration and the inactivation mechanisms of atmospheric air plasma and airborne acoustic ultrasound technologies for future real-world applications.

\section{Materials and methods}

Bacterial strains and culture conditions. Escherichia coli K-12 ER2925 and Listeria innocua NCTC 12,210 strains were used in our experiments, which were provided by Dr. Des Walsh from the microbiology culture collection at the Teagasc Food Research Centre. Stock cultures were maintained at $-80^{\circ} \mathrm{C}$, streaked onto tryptone soya agar CM0131 (TSA; Oxoid Limited, Ireland) and incubated at $37^{\circ} \mathrm{C}$ for $24 \mathrm{~h}$. Individual cultures were transferred to $10 \mathrm{ml}$ of tryptone soya broth CM0129 (TSB; Oxoid Limited, Ireland) and incubated at $37^{\circ} \mathrm{C}$ for $18 \mathrm{~h}$. After incubation, each culture was washed three times with $10 \mathrm{~mL}$ of phosphate buffered saline BR0014 
(PBS; Oxoid Limited, Ireland) at 7000 $\times g$ for $6 \mathrm{~min}$, re-suspended in $10 \mathrm{ml}$ of TSB and the concentration standardised to approximately $1 \times 10^{7} \mathrm{CFU} /$ coupon.

Preparation of coupons and biofilm formation. The biofilms were cultured on stainless steel (SS) coupons grade 304 (Watermark Engineering, Dublin, Ireland) of $15 \mathrm{~mm}$ diameter and $1.2 \mathrm{~mm}$ thickness. The coupons were sterilised by autoclaving at $121^{\circ} \mathrm{C}$ for $15 \mathrm{~min}$. For confocal laser scanning microscopy (CLSM) analysis, E. coli biofilms were produced on a glass coupon $(1 \times 1 \mathrm{~cm})$. To eliminate the presence of any residues on the glass coupons which could affect the microscopy data, the glass coupons were acid washed with $1 \mathrm{M} \mathrm{HCl}$ followed by $70 \%$ ethanol, as described by Fischer and co-workers ${ }^{38}$. The glass coupons were air dried in a fume hood and autoclaved at $121^{\circ} \mathrm{C}$ for $15 \mathrm{~min}$.

For biofilm formation on both SS and glass, $3 \mathrm{ml}$ of a standardised cell suspension was dispensed in each well of 12 well plates containing the sterilised coupons. The inoculated coupons were incubated for $48 \mathrm{~h}$ and $96 \mathrm{~h}$ at $37^{\circ} \mathrm{C}$ in an orbital shaker. After every $24 \mathrm{~h}$ incubation the TSB medium was replaced with equal volumes of fresh medium and incubation continued under the same conditions. To remove non-adherent cells, coupons were gently washed with $3 \mathrm{ml}$ of PBS. The coupons were then placed in a bio-safety cabinet to dry for 20-30 min before plasma or acoustic treatment.

Treatment of biofilms with atmospheric air plasma or acoustic airborne ultrasound technology. Atmospheric air plasma treatment $(A A P)$. The atmospheric air plasma used in this study was a multipin $(11 \times 8)$ plasma system (Leap100, PlasmaLeap Technologies, Dublin, Ireland). The discharge is generated between the ends of the high voltage pins and the flat ground base plate. The discharge gap was set to $55 \mathrm{~mm}$. Plasma was generated in the discharge gap using atmospheric air at varying discharge frequencies of $1000 \mathrm{~Hz}$, $2000 \mathrm{~Hz}$ and $2500 \mathrm{~Hz}$, at a fixed discharge voltage of $40 \mathrm{kV}$. The samples were treated with AAP for different treatment times ranging between 0 and $10 \mathrm{~min}$. Either 96 -well micro-titre plates containing $200 \mu \mathrm{l}$ of deionised water treated for reactive oxygen and nitrogen species (RONS) analysis, or petri dishes containing SS and glass coupons were placed directly between the electrodes for treatment. The lid of the container was removed during the plasma treatment process. Figure 8 a shows a schematic diagram of the bacterial coupon treatments using the multi-pin plasma system.

RONS analysis was carried out to investigate the optimal treatment parameters with the plasma system. The chemical composition and the $\mathrm{pH}$ were examined following 5 min of AAP treatment. Reactive species including hydrogen peroxide, nitrite and nitrate species generated by the plasma system in plasma treated water were analysed using a titanium oxysulfate calorimetric method, Griess reagent (N-(1-naphthyl) ethylenediamine dihydrochloride) and 2,6-dimethyl phenol (DMP) Spectroquant nitrate assay kit, as previously described by $\mathrm{Lu}$ et al. ${ }^{39}$. The $\mathrm{pH}$ of the treated water was measured using a SevenCompact $\mathrm{pH}$ meter (S210; Mettler-Toledo $\mathrm{GmbH}$, Switzerland).

Airborne acoustic ultrasound treatment (AAU). Airborne acoustic ultrasound treatments were carried out using an airborne ultrasonic system (Pusonics S.L., Madrid, Spain). The system was operated at a frequency of $26 \mathrm{kHz}$, with a maximum power output of $170 \mathrm{~W}$. A detailed description of the system has been previously described by Charoux et al. ${ }^{40}$. The biofilm coupons were placed on a stainless-steel plate at $42.5 \mathrm{~cm}$ from the focus centre of the transducer, where the maximum acoustic energy density of $10 \mathrm{~W} / \mathrm{cm}^{2}$ was located (Fig. $8 \mathrm{~b}$ ). The biofilm coupons were treated with airborne acoustics for 15 and $30 \mathrm{~min}$.

Quantification of intracellular reactive species generated by atmospheric air plasma treatment. The production of intracellular RONS in the biofilms was measured using $2^{\prime}, 7^{\prime}$-dichlorofluorescin diacetate (DCFH-DA; Sigma-Aldrich, Arklow, Ireland) assay and 4-amino-5-methylamino- 2',7'-difluorofluorescein diacetate (DAF-FM DA; Sigma-Aldrich, Arklow, Ireland) assay, as previously described by Han et al..$^{41}$, with minor modifications. Each treated or non-treated E. coli biofilm coupon was vortexed for 2 min with $10 \mathrm{ml}$ of $0.85 \% \mathrm{NaCl}$ solution and 10 glass beads (18406, Sigma-Aldrich, Arklow, Ireland). This bacterial suspension was used for the detection of intracellular RONS.

DCFH-DA was used to detect intracellular ROS, which could passively diffuse through the cell membrane and form non-fluorescent DCFH. The DCFH reacts with ROS to form fluorescent $2^{\prime}, 7^{\prime}$-dichlorofluorescein (DCF), which is trapped within the cell and measured using a fluorescence spectrophotometer. Treated and non-treated bacterial suspensions were incubated with DCFH-DA at a final concentration of $5 \mu \mathrm{M}$ in PBS for 15 min at $37^{\circ} \mathrm{C}$ in the dark. Incubated aliquots of $200 \mu \mathrm{l}$ were transferred into 96-well fluorescence micro-plates (Costar Multiple Well Cell Culture Plates, Fisher Scientific Ireland Ltd) and measured at excitation and emission wavelengths of $485 \mathrm{~nm}$ and $530 \mathrm{~nm}$ using a Spark multimode microplate reader (Tecan UK Ltd. UK).

DAF-FM DA was used to quantify intracellular RNS levels. DAF-FM DA is a cell permeable reagent, which is hydrolysed to 4-amino-5-methylamino-2',7'-difluororescein (DAF-FM) by intracellular esterase and reacts with NO inside the cell to yield benzotriazole which is highly fluorescent. AAP treated and non-treated E. coli cells were incubated with DAF-FM DA at a final concentration of $1 \mu \mathrm{M}$ in PBS for $15 \mathrm{~min}$ at $37^{\circ} \mathrm{C}$ in the dark. Samples were then transferred into new 96-well fluorescence microplates and measured at excitation and emission wavelengths of $490 \mathrm{~nm}$ and $515 \mathrm{~nm}$. Each sample was read in three wells and replicated twice. The intracellular RONS were measured immediately after AAP treatment. The percentage of mean fluorescence intensity was calculated by comparing the absorbance of the treated samples with the absorbance of the untreated control samples.

Determination of cell viability and metabolic activity. The viable counts in the biofilms on coupons before and after treatment were determined via plate counts. Untreated controls or treated biofilm SS coupons 


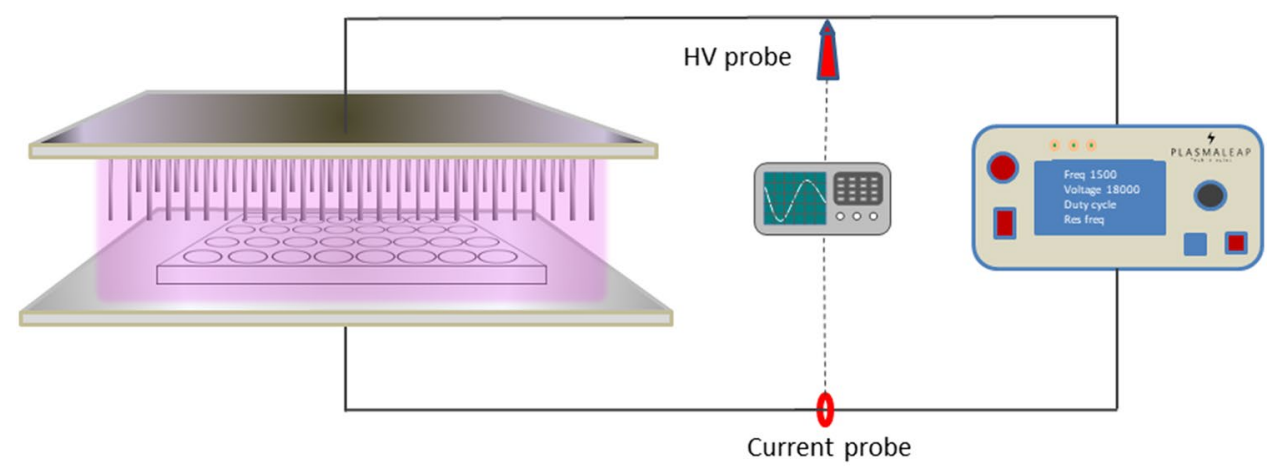

(a)

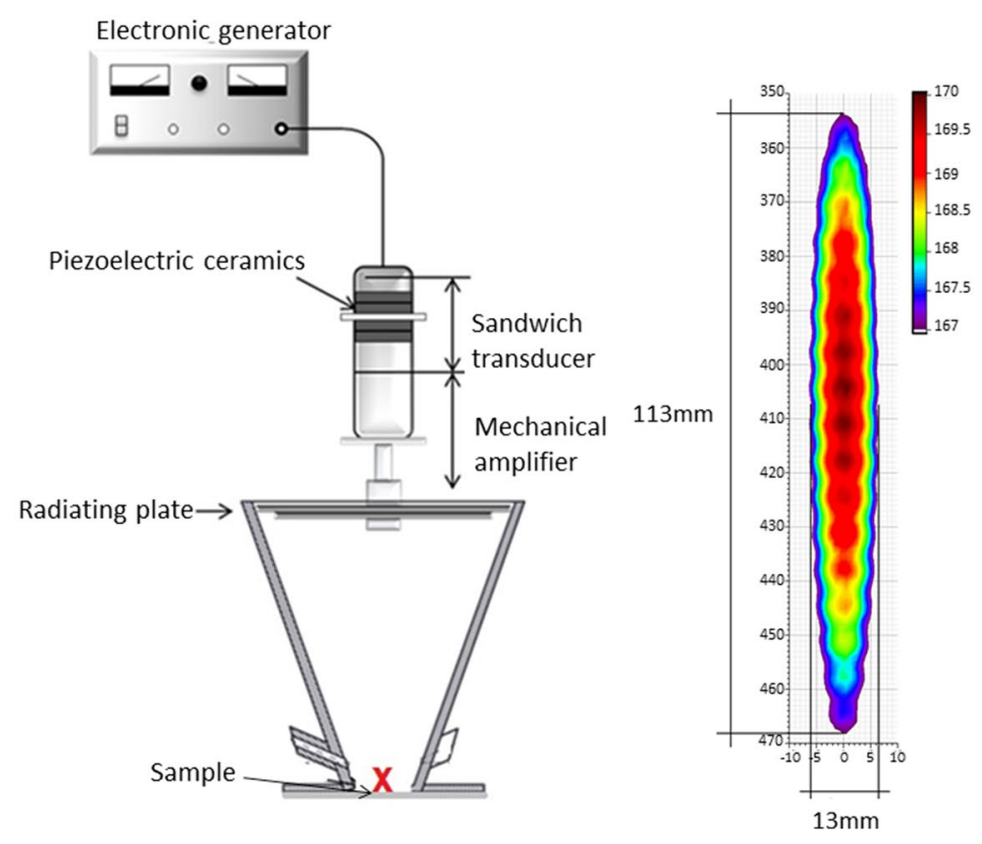

(b)

Figure 8. Schematic diagram of bacterial coupons treated with (a) atmospheric air plasma or (b) acoustic airborne ultrasound system and its intensity distribution.

were placed in a tube containing $10 \mathrm{ml}$ of maximum recovery diluent (MRD; Oxoid Ireland c/o Fannin Healthcare, Ireland) and 10 glass beads and vortexed for $2 \mathrm{~min}$ to disrupt any biofilm present on the coupons' surface. The resulting bacterial suspensions were serially diluted and plated on TSA plates and incubated for $24 \mathrm{~h}$ at $37^{\circ} \mathrm{C}$. Quantitative analysis was performed in duplicate for each experiment. The total viable count was determined by standard colony counts and expressed as logarithmic colony forming units ( $\log _{10} \mathrm{CFU} /$ coupon).

The metabolic activity of the bacterial cells before and after plasma and airborne acoustic treatments were determined by the XTT assay (2,3-bis(2-methoxy-4-nitro-5-sulfophenyl) [phenyl-amino) car-bonyl]-2H-tetrazolium hydroxide; XTT) as previously described by Peeters et al. $^{42}$, with a few modifications. A XTT stock solution was prepared by adding $4 \mathrm{mg}$ XTT (Sigma Aldrich, Arklow, Ireland) to $1 \mathrm{ml}$ of pre-warmed $1 \times \mathrm{PBS}$. This solution was supplemented with $100 \mu \mathrm{l}$ of menadione solution (containing $5.5 \mathrm{mg} / \mathrm{L}$ menadione (Sigma Aldrich, Arklow, Ireland) in acetone). The untreated/treated biofilm coupons were transferred to new 12-well tissue culture plates, and $300 \mu \mathrm{l}$ of freshly prepared XTT-menadione solution and $300 \mu \mathrm{l}$ of $1 \times$ PBS were placed on each biofilm coupon. After $5 \mathrm{~h}$ incubation at $37^{\circ} \mathrm{C}$ in the dark, the medium was removed and dispensed in sterile Eppendorf tubes. The medium was centrifuged for $5 \mathrm{~min}$ at $6000 \times \mathrm{g}$. For spectrophotometric readings, $100 \mu \mathrm{l}$ of supernatant was transferred to new 96-well microtiter plates and absorbance was read at $490 \mathrm{~nm}$. Untreated biofilm coupons were used as the control. The percentage of metabolic active cells was calculated by comparing the absorbance of the treated samples with the absorbance of the untreated control samples.

Bacterial staining for confocal laser scanning microscopy (CLSM) and fluorescence Live/Dead assay. Biofilms before and after treatment by AAP and AAU were stained using the Live/Dead BacLight Bacterial Viability kit L7007 (Thermofisher Scientific, Dublin, Ireland) according to the manufacturer's protocols. 
For confocal analysis, a fresh working solution was prepared by adding $1.5 \mu \mathrm{l}$ of each SYTO 9 and PI stain to $1 \mathrm{ml}$ of $0.85 \%$ sterile sodium chloride $(\mathrm{NaCl})$ solution. One hundred microliters of staining solution was added onto each biofilm coupon and incubated at room temperature in the dark for $15 \mathrm{~min}$. The coupons were washed gently with $\mathrm{NaCl}$ twice to remove excess stain and its residues. The stained samples were placed in $35 \mathrm{~mm}$ diameter glass-bottomed $\mu$-dish (ibidi GmbH, Martinsried, Germany) with a drop of mounting solution from the staining kit. Biofilms were visualised and imaged using a confocal laser scanning microscope (Olympus Fluoview FV1000) equipped with a 60×/1.35 NA oil immersion objective.

For microplate reader analysis, bacteria were re-suspended from the coupons' surface in $10 \mathrm{~mL}$ of sterile water using glass beads as described previously. Samples were stained by adding $100 \mu$ freshly prepared stain solution $(3 \mu \mathrm{l}$ SYTO $9+3 \mu \mathrm{l}$ PI working $+1 \mathrm{ml} 0.85 \% \mathrm{NaCl}$ solution) to $100 \mu \mathrm{l}$ bacterial suspension per well in a 96 -well fluorescence micro-plate (Costar Multiple Well Cell Culture Plates, Fisher Scientific Ireland Ltd). The stained samples were incubated at room temperature in the dark for $15 \mathrm{~min}$. Fluorescence intensity was measured with the Spark multimode microplate reader (Tecan UK Ltd. UK) using a $488 \mathrm{~nm}$ excitation filter (for both SYTO9 and PI) and a $530 \mathrm{~nm}$ (for SYTO 9) and $630 \mathrm{~nm}$ (for PI) emission filter.

Scanning electron microscope (SEM). SEM samples were prepared as previously described by Patange et al. ${ }^{9}$, with minor modifications. Following exposure to plasma or airborne acoustic treatment, SS coupons were fixed with $2.5 \%$ glutaraldehyde (Sigma-Aldrich, Arklow, Ireland) in $0.05 \mathrm{M}$ sodium cacodylate buffer (SCB; Fisher Scientific Ireland Ltd, Dublin, Ireland) ( $\mathrm{pH} 7.4)$ for $2 \mathrm{~h}$ at $4{ }^{\circ} \mathrm{C}$. After fixing, coupons were washed with SCB three times and fixed in $1 \%$ osmium tetroxide (Sigma-Aldrich, Arklow, Ireland) for $2 \mathrm{~h}$ at $4{ }^{\circ} \mathrm{C}$. The coupons were then rinsed once with SCB and twice with sterile distilled water. The fixed coupons were dehydrated using an increasing series of ethanol (30, 50, 70, 80, 95 and 99.5\%) for $5 \mathrm{~min}$ each and $15 \mathrm{~min}$ in 99.5\%. The coupons were then further dehydrated through a series of $33 \%, 50 \%, 66 \%$, and $100 \%$ of hexamethyldisilazane (HMDS; Sigma-Aldrich, Arklow, Ireland) prepared in $99.5 \%$ ethanol. The coupons were left to dry overnight in a fume hood. Samples were coated with gold using a Q150T ES sputtering device (Quorum Technologies Ltd, United Kingdom) and examined using a field emission scanning electron microscope (FE-SEM SU8240, Hitachi High Technologies, USA).

Treatment of biofilms with sodium hypochlorite. The working solution was prepared by diluting $12.5 \%$ sodium hypochlorite (VWR International Ltd., United Kingdom) in distilled water to obtain a final concentration of $200 \mathrm{ppm} \mathrm{NaOCl}$. The prepared $96 \mathrm{~h} \mathrm{E}$. coli biofilm coupon was immersed in $3 \mathrm{ml} \mathrm{NaOCl}$ solution and sterile distilled water (control) for 3, 5, 10, 15 and $30 \mathrm{~min}$. After treatment, samples were immediately neutralized by using $3 \mathrm{ml}$ sodium thiosulfate $(0.1 \mathrm{M})$ solution. The sample was then analysed by plate count and XTT assay as described before.

Statistical analysis. All experiments were carried out in duplicate and the data presented as means \pm standard deviations. Graphpad Prism version 5.0 (GraphPad software, San Diego, California, USA) was used for graphic representation and statistics calculations. One-way (ANOVA) followed by Tukey multiple comparison post hoc test was applied to evaluate the antimicrobial effect of the treatments and intracellular RONS levels. P values $<0.05$ were considered statistically significant.

Received: 12 May 2020; Accepted: 18 December 2020

Published online: 27 January 2021

\section{References}

1. Vishwakarma, V. Impact of environmental biofilms: Industrial components and its remediation. J. Basic Microbiol. 60, 198-206 (2020).

2. Percival, S. L., Suleman, L., Vuotto, C. \& Donelli, G. Healthcare-associated infections, medical devices and biofilms: Risk, tolerance and control. J. Med. Microbiol. 64, 323-334 (2015).

3. Galié, S., García-Gutiérrez, C., Miguélez, E. M., Villar, C. J. \& Lombó, F. Biofilms in the food industry: Health aspects and control methods. Front. Microbiol. 9, 898 (2018).

4. Flemming, H. C. et al. Biofilms: An emergent form of bacterial life. Nat. Rev. Microbiol. 14, 563-575 (2016).

5. Langsrud, S., Moen, B., Møretrø, T., Løype, M. \& Heir, E. Microbial dynamics in mixed culture biofilms of bacteria surviving sanitation of conveyor belts in salmon-processing plants. J. Appl. Microbiol. 120, 366-378 (2016).

6. Sharma, D., Misba, L. \& Khan, A. U. Antibiotics versus biofilm: An emerging battleground in microbial communities. Antimicrob. Resist. Infect. Control 8, 76 (2019).

7. Niemira, B. A., Boyd, G. \& Sites, J. Cold plasma inactivation of Escherichia coli O157:H7 biofilms. Front. Sustain. Food Syst. 2, 47 (2018).

8. Govaert, M. et al. Influence of plasma characteristics on the efficacy of Cold Atmospheric Plasma (CAP) for inactivation of Listeria monocytogenes and Salmonella typhimurium biofilms. Innov. Food Sci. Emerg. Technol. 52, 376-386 (2019).

9. Patange, A., Lu, P., Boehm, D., Cullen, P. J. \& Bourke, P. Efficacy of cold plasma functionalised water for improving microbiological safety of fresh produce and wash water recycling. Food Microbiol. 84, 103226 (2019).

10. Lu, X. et al. Reactive species in non-equilibrium atmospheric-pressure plasmas: Generation, transport, and biological effects. Phys. Rep. 630, 1-84 (2016).

11. Charoux, C. M. G., Ojha, K. S., O’Donnell, C. P., Cardoni, A. \& Tiwari, B. K. Applications of airborne ultrasonic technology in the food industry. J. Food Eng. 208, 28-36 (2017).

12. Gallo, M., Ferrara, L. \& Naviglio, D. Application of ultrasound in food science and technology: A perspective. Foods 7, 164 (2018).

13. Chang, Y. J. R., Perry, J. \& Cross, K. Low-frequency ultrasound debridement in chronic wound healing: A systematic review of current evidence. Plast. Surg. 25, 21-26 (2017).

14. Murphy, C. A., Houghton, P., Brandys, T., Rose, G. \& Bryant, D. The effect of $22.5 \mathrm{kHz}$ low-frequency contact ultrasound debridement (LFCUD) on lower extremity wound healing for a vascular surgery population: A randomised controlled trial. Int. Wound J. 15, 460-472 (2018). 
15. Ashokkumar, M. The characterization of acoustic cavitation bubbles-An overview. Ultrason. Sonochem. 18, 864-872 (2011).

16. Collis, J. et al. Cavitation microstreaming and stress fields created by microbubbles. Ultrasonics 50, 273-279 (2010).

17. Pan, J. et al. Investigation of cold atmospheric plasma-activated water for the dental unit waterline system contamination and safety evaluation in vitro. Plasma Chem. Plasma Process. 37, 1091-1103 (2017).

18. Walsh, J. L., Iza, F., Janson, N. B., Law, V. J. \& Kong, M. G. Three distinct modes in a cold atmospheric pressure plasma jet. J. Phys. D. Appl. Phys. https://doi.org/10.1088/0022-3727/43/7/075201 (2010).

19. Walsh, J. L., Cao, Z. \& Kong, M. G. Atmospheric dielectric-barrier discharges scalable from $1 \mathrm{~mm}$ to $1 \mathrm{~m}$. IEEE Trans. Plasma Sci. https://doi.org/10.1109/TPS.2008.924518 (2008).

20. Bourke, P., Ziuzina, D., Han, L., Cullen, P. J. \& Gilmore, B. F. Microbiological interactions with cold plasma. J. Appl. Microbiol. 123, 308-324 (2017).

21. Patange, A. et al. The effect of atmospheric cold plasma on bacterial stress responses and virulence using Listeria monocytogenes knockout mutants. Front. Microbiol. 10, 2841 (2019).

22. Jiang, S. et al. Effect of the biofilm age and starvation on acid tolerance of biofilm formed by Streptococcus mutans isolated from caries-active and caries-free adults. Int. J. Mol. Sci. 18, E713 (2017).

23. Soler-Arango, J., Figoli, C., Muraca, G., Bosch, A. \& Brelles-Mariño, G. The Pseudomonas aeruginosa biofilm matrix and cells are drastically impacted by gas discharge plasma treatment: A comprehensive model explaining plasma-mediated biofilm eradication. PLoS ONE 14, e0216817 (2019).

24. Bi, X. et al. Effects of combination treatments of lysozyme and high power ultrasound on the Salmonella typhimurium inactivation and quality of liquid whole egg. Ultrason. Sonochem. 60, 104763 (2020).

25. Gilmore, B. F. et al. Cold plasmas for biofilm control: Opportunities and challenges. Trends Biotechnol. 36, 627-638 (2018).

26. Ziuzina, D., Boehm, D., Patil, S., Cullen, P. J. \& Bourke, P. Cold plasma inactivation of bacterial biofilms and reduction of quorum sensing regulated virulence factors. PLOS ONE 10, e0138209 (2015).

27. Van Impe, J. et al. State of the art of nonthermal and thermal processing for inactivation of micro-organisms. J. Appl. Microbiol. 125, 16-35 (2018).

28. Los, A., Ziuzina, D., Boehm, D., Cullen, P. J. \& Bourkea, P. Inactivation efficacies and mechanisms of gas plasma and plasma-activated water against Aspergillus flavus spores and biofilms: A comparative study. Appl. Environ. Microbiol. https://doi.org/10.1128/ AEM.02619-19 (2020).

29. Kondeti, V. S. S. K. et al. Long-lived and short-lived reactive species produced by a cold atmospheric pressure plasma jet for the inactivation of Pseudomonas aeruginosa and Staphylococcus aureus. Free Radic. Biol. Med. 124, 275-287 (2018).

30. Schnabel, U. et al. Antimicrobial efficiency of non-thermal atmospheric pressure plasma processed water (PPW) against agricultural relevant bacteria suspensions. Int. J. Environ. Agric. Res. 2(5), 212-224 (2016).

31. Song, K.-Y., Chon, J.-W., Kim, H., Park, C. \& Seo, K.-H. Sodium hypochlorite-mediated inactivation of Cronobacter spp. biofilms on conveyor belt chips. Food Sci. Biotechnol. 23, 1893-1896 (2014).

32. Van Haute, S., Sampers, I., Holvoet, K. \& Uyttendaelea, M. Physicochemical quality and chemical safety of chlorine as a reconditioning agent and wash water disinfectant for fresh-cut lettuce washing. Appl. Environ. Microbiol. https://doi.org/10.1128/AEM.03283 -12 (2013).

33. Pereira, S. S. P., de Oliveira, H. M., Turrini, R. N. T. \& Lacerda, R. A. Disinfection with sodium hypochlorite in hospital environmental surfaces in the reduction of contamination and infection prevention: A systematic review. Rev. da Esc. Enferm. 49, 681-688 (2015).

34. Micciche, A. C. et al. The implementation and food safety issues associated with poultry processing reuse water for conventional poultry production systems in the United States. Front. Sustain. Food Syst. https://doi.org/10.3389/fsufs.2018.00070 (2018).

35. Meireles, A., Giaouris, E. \& Simões, M. Alternative disinfection methods to chlorine for use in the fresh-cut industry. Food Res. Int. 82, 71-85 (2016).

36. Kampf, G. Biocidal agents used for disinfection can enhance antibiotic resistance in gram-negative species. Antibiotics 7, 110 (2018).

37. Wang, H., Cai, L., Li, Y., Xu, X. \& Zhou, G. Biofilm formation by meat-borne Pseudomonas fluorescens on stainless steel and its resistance to disinfectants. Food Control 91, 397-403 (2018).

38. Fischer, A. H., Jacobson, K. A., Rose, J. \& Zeller, R. Preparation of slides and coverslips for microscopy. Cold Spring Harb. Protoc. 2008, pdb.prot49 (2008).

39. Lu, P., Boehm, D., Bourke, P. \& Cullen, P. J. Achieving reactive species specificity within plasma-activated water through selective generation using air spark and glow discharges. Plasma Process Polym. 14(8), 1600207 (2017).

40. Charoux, C. M. G., O’Donnell, C. P. \& Tiwari, B. K. Effect of airborne ultrasonic technology on microbial inactivation and quality of dried food ingredients. Ultrason. Sonochem. 56, 313-317 (2019).

41. Han, L., Boehm, D., Milosavljević, V., Amias, E. \& Cullen, P. Atmospheric cold plasma interactions with modified atmosphere packaging inducer gases for safe food preservation. Innov. Food Sci. Emerg. Technol. https://doi.org/10.1016/j.ifset.2016.09.026 (2016).

42. Peeters, E., Nelis, H. J. \& Coenye, T. Comparison of multiple methods for quantification of microbial biofilms grown in microtiter plates. J. Microbiol. Methods 72, 157-165 (2008).

\section{Acknowledgements}

The authors would also like to thank Dr. Ian Reid for scanning electron microscopic imaging. This research was funded by Science Foundation Ireland (SFI) under grant number 17/CDA/4653.

\section{Author contributions}

B.T. and A.P. conceived the idea and designed the experiments. A.P. performed experiments and wrote the manuscript. J.S, A.P performed and analysed confocal images. B.T., J.C., J.S., P.J. and C.B. edited the manuscript. All authors discussed and reviewed the manuscript.

\section{Competing interests}

Author PJ Cullen is CEO of PlasmaLeap Technologies, the supplier of the plasma technology employed for the generation of plasma in this study. The other authors declare no competing interests.

\section{Additional information}

Correspondence and requests for materials should be addressed to A.D.P.

Reprints and permissions information is available at www.nature.com/reprints. 
Publisher's note Springer Nature remains neutral with regard to jurisdictional claims in published maps and institutional affiliations.

(c) (i) Open Access This article is licensed under a Creative Commons Attribution 4.0 International License, which permits use, sharing, adaptation, distribution and reproduction in any medium or format, as long as you give appropriate credit to the original author(s) and the source, provide a link to the Creative Commons licence, and indicate if changes were made. The images or other third party material in this article are included in the article's Creative Commons licence, unless indicated otherwise in a credit line to the material. If material is not included in the article's Creative Commons licence and your intended use is not permitted by statutory regulation or exceeds the permitted use, you will need to obtain permission directly from the copyright holder. To view a copy of this licence, visit http://creativecommons.org/licenses/by/4.0/.

(C) The Author(s) 2021 